\title{
Administraciónd
}

\section{Reflexiones sobre las éticas en la gestión pública}

Hablar de tendencias éticas en la gestión pública nos lleva a reflexionar en tres direcciones, la primera tendencia se inscribe en lo que se ha venido denominando la administración pública tradicional en el que la interpretación del "interés público" es definida por políticos y por la expertise burocrática y, el modelo dominante de accountability es formal y jerárquica. La segunda tendencia la podemos ubicar en la Nueva Gestión Pública (NGP) cuyo enfoque principal es la satisfacción de usuarios en la búsqueda de eficiencia y eficacia en los servicios públicos. A ello le corresponde un comportamiento ético basado en el cumplimiento de resultados. Y la tercera tendencia se relaciona con la gestión pública basada en la creación de valor público donde se enfatiza por una ética pública basada en la conjunción de la libertad individual y civil con la autoridad legítima del Estado que exige participación democrática, donde la rendición de cuentas y la participación ciudadana son elementos clave. El objetivo de esta ponencia es justamente analizar la ética en el contexto de las tendencias de la gestión pública, esto requiere darle un sentido a la ética pública o ética para la política y la administración pública.

Palabras clave: Administración pública, gestión pública, valor público, ética pública.

\section{abstract}

Reflections on ethics in public management

Dealing with ethical trends in governance leads to three directions of thought. Firstly, that in keeping with what has been called traditional public administration where public interest is interpreted by politicians and bureaucratic experts and the dominant model of accountability is formal and hierarchical. The second area deals with new public management (NPM) whose primary focus is user satisfaction; the search for public service performance and efficiency underlies such approach and involves ethical behaviour based on achieving results (i.e. compliance). The third area is based on creating public value, emphasised by public ethics grounded on the conjunction of individual and civil liberties with the state's legitimate authority which requires democratic participation, accountability and citizen participation forming key elements. This paper was aimed at analysing ethics within the context of trends in public management, implying a sense of direction for public ethics or ethics involved in policy-making and public administration. Key words: public administration, public management, public values, public ethics.

\section{resumo}

Reflexóes sobre a ética na gestão pública

Falar sobre tendências éticas na gestáo pública nos leva a refletir em três direçóes; a primeira tendência esta inserida no que vêm sendo denominada Administraçáo Pública Tradicional, onde a interpretaçáo do "interesse público" é definida pelos políticos e pela expertise burocrática e o modelo dominante de accountability é formal e hierárquico. A segunda tendência é encontrada na Nova Gestáo Pública (NGP) cujo escopo principal é satisfazer aos usuários, à procura de eficiência e eficácia nos serviços públicos. A isto corresponde um comportamento ético baseado nos objetivos cumpridos. E a terceira tendência relaciona-se com a gestáo pública baseada na criaçáo do valor público, onde se enfatiza por uma ética pública baseada na conjunçáo da liberdade individual e civil com a autoridade legítima do Estado que exige participaçáo democrática e onde os informes públicos e a participaçáo da cidadania săo elementos chave. O objetivo desta palestra e justamente analisar a ética no contexto das tendências de gestão pública, e isto exige outorgar um sentido para a ética pública ou a ética para a política e a administraçáo pública.

Palavras chave: Administraçāo pública, gestão pública, valor público, ética pública.

Recibido: julio de 2011 / Aprobado: octubre de 2011

CORREO IMPRESO: Avenida Fundadores y Rufino Tamayo, C.P. 66269, San Pedro Garza García, Nuevo León, México.

\section{FREDDY MARIÑEZ NAVARRO*}

\section{Introducción}

En los últimos años, los países de América Latina han experimentado reformas importantes en el Estado y particularmente en la Administración Pública. En este sentido, la cuestión de la ética aparece junto a estas transformaciones y cambios -al menos en el debate teórico-. La adopción de códigos, de regulaciones éticas, así como de sistemas de transparencia y rendición de cuentas es prueba del rol que ha venido jugando la ética en todos estos procesos. En la década de los 90, la OCDE introduce un conjunto de recomendaciones en esta dirección, proponiendo los siguientes principios para el manejo de la ética en el servicio público (OECD, 1998): claridad en los estándares éticos; reflejo de los estándares éticos en los marcos legales; disponibilidad de una guía ética para el servidor público; conocimiento por parte de los servidores públicos de sus derechos y obligaciones; establecimiento de comités políticos que refuercen la conducta ética del servidor público; transparencia y apertura al escrutinio público de los procesos de tomas de decisión; guías claras para la interacción entre los sectores público-privado; demostración por parte de los funcionarios de conductas éticas; promoción de una conducta ética en las prácticas, procesos y políticas de gestión; incorporación de mecanismos adecuados de accountability en el servicio público y, establecimiento de procedimientos y sanciones. Varios enfoques sobre la ética en los servicios públicos también han sido validados (Maesschalk, J; 2004), por un lado, la denominada "obediencia" que enfatiza en la importancia de los controles externos en el comportamiento de los servidores públicos, y el enfoque de la "integridad" que focaliza sobre el autocontrol ejercido por cada servidor público. Así, el marco ético o la infraestructura ética son los elementos que los actores gubernamentales consideran importantes para el propio funcionamiento del servicio público.

Afirmamos que estas reformas, inquietudes y estilos de gestión pública han generado comportamientos éticos específicos. En consecuencia, este trabajo explora estos comportamientos, iden-

* Director de la Maestría en Administración Pública de la EGAP - Gobierno y Política Pública, Tecnológico de Monterrey, Campus Monterrey, México. CORREO-E: fmarinez@itesm.mx 
tificados en las tres tendencias siguientes: la primera se inscribe en lo que se ha venido denominando la administración pública tradicional y que corresponde a un comportamiento ético sustentado en la unipresencia del Estado en la regulación de la vida social, por lo que la sociedad civil le debe obediencia dado que la única legitimidad es la agregativa (el voto). En este sentido, la interpretación del "interés público" es definida por políticos y por la expertise burocrática y, el modelo dominante de accountability es formal y jerárquico. La segunda tendencia la podemos ubicar en la Nueva Gestión Pública (NGP) cuyo enfoque principal es la satisfacción de usuarios en la búsqueda de eficacia en los servicios públicos. A ello le corresponde un comportamiento ético basado en el cumplimiento de resultados que justifican recursos o procedimientos como la gestión de insumos y productos. Y la tercera tendencia se relaciona con la gestión pública basada en la creación de valor público, que se caracteriza porque toma los mandatos como puntos de partida, y no como fines por sí mismos. Este tipo de gestión también se enfoca en los resultados operativos (su productividad, efectividad y eficiencia), pero desde la importancia y pertinencia del impacto, de tal manera que amplía la forma en la que se mide el desempeño del gobierno y guía las decisiones sobre políticas públicas. En esta tendencia de gestión pública, se ubica una ética pública basada en la conjunción de la libertad individual y civil con la autoridad legítima del Estado que exige participación democrática, donde la rendición de cuentas y la participación ciudadana son elementos clave. Para darle una ubicación a las visiones de la ética de la gestión pública, nos basaremos en el esquema de Kelly y Muers (2002):

\begin{tabular}{|c|c|c|c|}
\hline & \begin{tabular}{|} 
Administración \\
Pública \\
Tradicional
\end{tabular} & $\begin{array}{l}\text { Nueva Gestión } \\
\text { Pública }\end{array}$ & $\begin{array}{l}\text { Generación de } \\
\text { Valor Público }\end{array}$ \\
\hline $\begin{array}{l}\text { Enfoque } \\
\text { principal }\end{array}$ & $\begin{array}{c}\text { Cumplimiento de } \\
\text { Mandatos }\end{array}$ & $\begin{array}{c}\text { Satisfacción } \\
\text { de usuarios. Eficiencia, } \\
\text { eficacia en los servicios }\end{array}$ & $\begin{array}{l}\text { Respuesta a ciudada- } \\
\text { nos y usuarios }\end{array}$ \\
\hline $\begin{array}{l}\text { Interpretación } \\
\text { del "interés } \\
\text { público" }\end{array}$ & $\begin{array}{l}\text { Definido por } \\
\text { políticos o } \\
\text { expertos }\end{array}$ & $\begin{array}{l}\text { Agregado de prefe- } \\
\text { rencias individuales, } \\
\text { evidenciadas por elec- } \\
\text { ciones en el mercado }\end{array}$ & $\begin{array}{c}\text { Preferencias públicas } \\
\text { en deliberaciones en } \\
\text { la arena política }\end{array}$ \\
\hline $\begin{array}{l}\text { Modelo } \\
\text { dominante de } \\
\text { Accountability }\end{array}$ & $\begin{array}{c}\text { Hacia arriba, for- } \\
\text { mal, jerárquico }\end{array}$ & $\begin{array}{c}\text { Hacia arriba, por } \\
\text { medio de contratos de } \\
\text { desempeño }\end{array}$ & Múltiple, interactivo \\
\hline $\begin{array}{l}\text { Sistema } \\
\text { de entrega } \\
\text { Preferido }\end{array}$ & Jerárquico & $\begin{array}{l}\text { Privado o público con } \\
\text { gestión distante }\end{array}$ & Múltiple \\
\hline
\end{tabular}

\begin{tabular}{|c|c|c|c|}
\hline & \begin{tabular}{|c|} 
Administración \\
Pública \\
Tradicional
\end{tabular} & $\begin{array}{l}\text { Nueva Gestión } \\
\text { Pública }\end{array}$ & $\begin{array}{l}\text { Generación de } \\
\text { Valor Público }\end{array}$ \\
\hline $\begin{array}{c}\text { Instrumentos } \\
\text { principales }\end{array}$ & $\begin{array}{l}\text { Gestión de } \\
\text { insumos }\end{array}$ & $\begin{array}{l}\text { Gestión de insumos y } \\
\text { Productos }\end{array}$ & $\begin{array}{l}\text { Gestión de servicios, } \\
\text { Satisfacción, } \\
\text { resultados, confianza, } \\
\text { legitimidad del } \\
\text { Gobierno }\end{array}$ \\
\hline $\begin{array}{l}\text { Rol de la } \\
\text { participación } \\
\text { Ciudadana }\end{array}$ & $\begin{array}{c}\text { Voto por } \\
\text { representantes } \\
\text { gubernamentales }\end{array}$ & $\begin{array}{c}\text { Voto por representantes } \\
\text { gubernamentales, } \\
\text { uso de encuestas de } \\
\text { satisfacción }\end{array}$ & Multifacética \\
\hline $\begin{array}{c}\text { Metas } \\
\text { gerenciales }\end{array}$ & $\begin{array}{l}\text { Respuestas a } \\
\text { autoridades } \\
\text { Políticas }\end{array}$ & Metas de desempeño & $\begin{array}{c}\text { Metas relacionadas } \\
\text { con respuestas a } \\
\text { los ciudadanos/ } \\
\text { usuarios, confianza y } \\
\text { legitimidad }\end{array}$ \\
\hline
\end{tabular}

Fuente: Kelly y Muers, 2002

El objetivo de esta ponencia es justamente analizar la ética en el contexto de las tendencias de la gestión pública, esto requiere darle un sentido a la ética pública o ética para la política y la administración pública. Es decir, aquella ética que señala qué deben hacer los poderes, las autoridades y los funcionarios, quiénes pueden y son competentes para hacerlo y con qué procedimientos, precisamente para que los ciudadanos sean libres en la orientación de su moralidad privada (Gregorio Peces-Barbas: 2004). Partiendo de esto, la administración pública entonces debe sujetarse a la legalidad para proveer servicios públicos con eficacia y transparencia. Por lo que es importante rescatar a Norberto Bobbio (1997), cuando expresa que el buen gobierno debe distinguirse del malo por dos criterios: uno, el gobierno para el bien común, que es diferente al gobierno para el bien propio; y dos, el gobierno que se ejerce de acuerdo con las leyes establecidas.

\section{La ética de la administración pública tradicional}

La perspectiva de la acción gubernamental se caracteriza justamente por el estadocentrismo. Esto ha implicado que el Estado históricamente haya adquirido rasgos muy pronunciados en el ejercicio del control autoritario de aparatos burocráticos, así como la movilización de recursos y soportes. Este control y estos recursos y soportes se expresan a través de reglamentaciones donde la organización estatal pone un marco y límites a las actividades de los actores, apareciendo esta como la única defensora del orden público y de la regulación social. Este poder estatal es necesario para que el Estado 
llene su función esencial que ha hecho de este el regulador del orden y del movimiento, articulando las funciones generales de reproducción social y de reproducción del complejo organizacional. Georges Burdeau afirma que "el Estado es asiento de un poder cuyos gobiernos son los agentes en ejercicio. Asiento de un poder quiere decir que este encarna una idea de derecho" (1992:109). Es ahí justamente donde reposa la legitimación de la dominación o del poder autoritario del mandamiento constitucional o legal. Es basada sobre esta característica que Max Weber explica que "el tipo más puro de dominación legal es aquel que se ejerce por medio de un cuadro administrativo burocrático" (1997:175).

El mismo Max Weber presenta una definición de Estado que apunta a poner en relación una estructura de poder legítima (la organización), una distribución del poder (el monopolio de la fuerza física), un conjunto de funciones (coerción), un campo de acción específico (el territorio) y una manera particular de construir este campo (el monopolio de la violencia). Bajo todas estas relaciones de carácter weberiano, el poder del Estado se ha podido expresar en fuerza pública y en autoridad pública; la primera, nos lleva a utilizar los medios de coerción física ya que el Estado tiene el monopolio de la fuerza. La segunda reposa sobre la confianza que los órganos del Estado inspiran a los ciudadanos.

Por otro lado, y en cuanto al carácter regulador del aparato estatal, es pertinente, dada su relación con las decisiones públicas y las acciones gubernamentales, la aproximación que tiene David Easton (1965) sobre los sistemas políticos en el momento que considera la vida política como un sistema de comportamiento, inserta aquella en un ambiente de influencias a las cuales este mismo está expuesto y reacciona. Así, para que un sistema político se distinga de otro sistema, se le puede observar el cumplimiento exitoso de dos funciones distinguidas por interacciones políticas: asignar valores para una sociedad, y lograr que la mayoría de sus miembros acepten estas asignaciones como obligatorias, al menos la mayor parte del tiempo" (1997:223).

Este concepto de sistema político es considerado como un conjunto de intercambios (Input-output). El Input (insumos), consiste en agregados que concentran y reflejan todo lo que concierne a las tensiones políticas, y por cuyas consecuencias, estas serán transformadas y organizadas en output (productos), engendrando lo que se denomina el "bucle de retroalimentación" que actuaría como factor de regulación del sistema. Cabe señalar que los efectos de los insumos en las decisiones y acciones gubernamentales es un elemento importante en este concepto de sistema ya que "saber quién controla a quién en los diversos procesos de toma de decisiones, seguirá siendo una preocupación vital, puesto que la pauta de las relaciones de poder ayuda a determinar la índole de los productos" (1997:228), que se reflejan en reglamentos, políticas públicas y leyes. Es la manera en que el sistema hace frente a las tensiones del sistema mediante la retroalimentación. Se precisa entonces que la acción del sistema tiene personas que suelen hablar en nombre de él y estas son las autoridades que toman decisiones para satisfacer demandas o crear las condiciones que la satisfagan.

Vemos así que el término público se centra en la interacción y relaciones en el sistema político por lo que se refiere a los políticos y administradores (burocracia) que toman las decisiones y de quienes se quiere tener la seguridad de su capacidad administrativa (Jean-Claude Thönig; 1997). Esta característica, vista también por Woodrow Wilson ((2005, [1887]), es la clásica dicotomía de la administración pública: políticos vs administradores públicos. Y es justamente por esta vía que se distribuyen cosas valoradas entre personas y grupos siguiendo uno o más de tres procedimientos posibles (David Easton): privando a la persona de algo valioso que poseía, entorpeciendo la consecución de valores que de lo contrario se habrían alcanzado, o bien permitiendo el acceso a los valores a ciertas personas y negándolo a otras.

Es importante asumir con Nicholas Henry (2001) que la administración pública se originó de la ciencia política y su desarrollo inicial ocurrió en su interior, por lo que los preceptos fundamentales de esta disciplina -el pluralismo, la visión sistémica de la política y los conceptos constitucionales del país-, sirvieron de premisas de la administración pública ${ }^{1}$.

\footnotetext{
"Robert Dahl analizó el estado de la disciplina de administración pública en su artículo de 1947 publicado en la Public Administration Review, (La ciencia de la administración pública). Precisó algunas acciones para una disciplina que pronto surgió por sus propios méritos; sin embargo, lo más significativo que Dahl advirtió a los teóricos era que, para que la administración pública fuese aceptada como ciencia política (el campo de estudio de la mayor parte de las academias de administración pública), la doctrina prevaleciente de que administración es política tendría que ser más que una simple revelación: había que crear una ciencia de la administración pública que plantee honestamente los fines y que i) reconozca las complejidades de la conducta humana; ii) trate acerca de los problemas de valores normativos en
} 
De esta manera, la función de la Ciencia Política era describir los principios que serían adheridos a las cuestiones públicas y al estudio de las operaciones de los gobiernos para demostrar lo que es bueno, criticar lo que es malo o ineficiente y para sugerir mejoras. O como decía Karl Duetsch «el conjunto de las decisiones tomadas por medios públicos, constituye el sector público de un país o sociedad» (Deutsch, Karl W; 1993:15). Planteado en esta perspectiva, E. Pendleton Herring [1936] afirmó en su interesante libro Public Administration and Public Interest, que el interés público es... "la norma que guía al administrador al aplicar la ley. Este es el símbolo verbal planeado para introducir, unidad, orden y objetividad en la administración" (Jay M. Shafritz y Albert C. Hyde; 1999:181-188).

Se perfila entonces que el modelo de burocracia como propuesta organizativa, debe estructurarse sobre la base de las siguientes características (Weber; 1997):

a. Carácter legal de las normas y de los reglamentos.

b. Carácter formal de las comunicaciones.

c. Racionalidad en la división del trabajo.

d. Impersonalidad en las relaciones de trabajo.

e. Jerarquía bien establecida de la autoridad.

f. Rutinas y procedimientos de trabajo estandarizados en guías y manuales.

g. Competencia técnica y meritocrática vinculada a la secuencia profesional y legal.

h. Especialización de la administración y de los administradores, como una clase separada $y$ diferenciada de la propiedad (los accionistas).

i. Completa previsibilidad del funcionamiento.

Bajo esta visión burocrática, Max Weber (1998), parte del concepto de ética basada en principios y ética basada en responsabilidad. Este término se relaciona con responder por lo hecho, de nuestros propios actos y de las consecuencias de ellos derivadas ante uno mismo (conciencia) o ante alguien. No es más que "prometer solemnemente", "dar la palabra".

situaciones administrativas, y iii) tenga en cuenta la relación entre la administración pública y su medio social” (Jay M. Shafritz y Albert C. Hyde; 1999:171-172).
Si no pudimos actuar de otro modo, si el hombre no es dueño de sus actos (acto moral), si carece de la capacidad de autodeterminarse, no debe sentirse responsable. Por eso, al hablar de los actos morales, se enumeran una serie de circunstancias atenuantes o dirimentes que modifican la responsabilidad del acto moral, como la ignorancia de las circunstancias y consecuencias del mismo. Se trata aquí sólo de apegarse a la legalidad, mientras un funcionario público cumpla con lo establecido en las normas, se está cumpliendo con la ética pública. De esta manera, cualquier gobierno estará legitimado si defiende y aplica una ética pública de esta naturaleza ya que esta conlleva responsabilidad, espíritu de servicio, atención y justicia para el ciudadano. Es decir, se debe contar con la probidad del burócrata. En su interesante trabajo denominado Democracia y administración pública: la conexión emergente, Guy B. Peters (2006), afirma lo siguiente:

Allí donde se ha hablado de la burocracia en términos democráticos, la descripción ha obedecido generalmente a una concepción pasiva de la democracia (...). Como mínimo, la burocracia garantiza un tratamiento igualitario para todos los ciudadanos. Además, una presuposición que ha sido muy influyente es que, si se hace que la burocracia represente mejor a la sociedad, y si se le infunden los valores democráticos apropiados, esta satisfará, como mínimo, los requisitos básicos de comportamiento en un contexto político democrático. Esta concepción pasiva de la democracia con respecto a la burocracia dista de ser irrelevante, pero puede resultar insuficiente en sistemas democráticos contemporáneos dominados por el ejecutivo político. En los sistemas políticos contemporáneos puede ser necesaria una concepción más activa de la democracia dentro de la burocracia, y debemos comprender que la burocracia tiene el potencial necesario para ser una institución democrática importante (2006:31).

Para los efectos de precisar la concepción activa y pasiva de la burocracia en la administración pública, es decir, para que aquella se convierta en actor importante en las sociedades democráticas contemporáneas, Guy B. Peters lo esquematiza de la siguiente manera: 


\begin{tabular}{|l|l|l|}
\hline & \multicolumn{1}{|c|}{ Pasiva } & \multicolumn{1}{c|}{ Activa } \\
\hline Inclusión social & Burocracia representativa & Implicación ciudadana \\
\hline $\begin{array}{l}\text { Elaboración de } \\
\text { políticas }\end{array}$ & $\begin{array}{l}\text { Receptividad a las aporta- } \\
\text { ciones }\end{array}$ & $\begin{array}{l}\text { Consumación, deliberación, } \\
\text { creación consensuada de } \\
\text { normas }\end{array}$ \\
\hline $\begin{array}{l}\text { Implicación } \\
\text { directa }\end{array}$ & Implementación & Igualdad/Equidad \\
\hline Inclusión & Gestión & $\begin{array}{l}\text { Tratamiento igualitario de } \\
\text { los empleados }\end{array}$ \\
\hline Desempeño & $\begin{array}{l}\text { Atribución de responsabili-- } \\
\text { dades }\end{array}$ & Parlamentaria \\
\hline $\begin{array}{l}\text { Relación cliente/ } \\
\text { servicio }\end{array}$ & Probidad weberiana & Centrada en valores \\
\hline
\end{tabular}

Fuente: Guy B. Peters, 2006

\section{La Nueva Gestión Pública y la ética de los resultados}

Es de común aceptación entre autores especialistas sobre la nueva forma de gobernar que el debate sobre este, desarrollado en las últimas décadas, ha tenido un eje clave común y es que el Estado ha dejado de tener el monopolio sobre los conocimientos y sobre los recursos políticos e institucionales necesarios para gobernar, así como la tendencia creciente de la influencia de actores no gubernamentales en las decisiones públicas.

Autores como B. Guy Peters (2003), Jan Kooiman (2004), Luis F. Aguilar Villanueva (2007), R. Mayntz (2001), entre otros, han venido planteando que estos cambios se deben a factores diferentes. Por una parte, la necesidad de alcanzar mayor eficiencia en la producción de servicios para reducir el gasto público dada la crisis fiscal del Estado; también, por la pérdida de certidumbre sobre un centro de control político eficaz -capacidades del Estado-, que ha venido generando alternativas de coordinación entre lo político y lo social; otro factor es el explicado desde la perspectiva de la globalización que los ve como unas de sus consecuencias: la pérdida de la habilidad tradicional del Estado para dirigir la sociedad y la transferencia de competencias a instituciones internacionales, y las que se generan de la desregulación de los mercados internacionales. Por otro lado, antecedidos por los conceptos o paradigmas posburocráticos, primero el establecido por Micheal Barzelay (2000:117), en el que propone sustituir la frase "interés Público" por "los resultados que valoran los ciudadanos"; y segundo, por los conceptos de Osborne y Geabler (1997) que expresaban el espíritu empresarial en la gestión pública, vemos la emergencia de la Nueva Gestión Pública (NGP), que trajo aparejada una nueva gestión de lo público donde confluyen según B. Guy Peters (2001), cuatro modelos de gobierno administrativo: el desregulado, el flexible, el de mercado y el participativo.

Esta nueva forma de administrar lo público tiene como objetivo la búsqueda de un sector público que funcione sólo en aquellas áreas con criterio de eficacia y resultados. Christopher Hood (1991), quien empieza a desmontar el modelo de Administración Pública tradicional logra construir una propuesta de Nueva Gestión Pública sobre estas bases:

\begin{tabular}{|c|c|c|c|}
\hline No. & Doctrina & Significado & Justificación \\
\hline 1 & $\begin{array}{l}\text { Profesionales } \\
\text { prácticos en la } \\
\text { administración del } \\
\text { sector público }\end{array}$ & $\begin{array}{l}\text { Control discrecional } \\
\text { activo y visible en las } \\
\text { organizaciones }\end{array}$ & $\begin{array}{l}\text { La rendición de cuentas } \\
\text { (accountability) requiere } \\
\text { claridad en la asigna- } \\
\text { ción de responsabilidad }\end{array}$ \\
\hline 2 & $\begin{array}{l}\text { Estándares explíci- } \\
\text { tos de medición en } \\
\text { el actuar }\end{array}$ & $\begin{array}{c}\text { Definición de metas, } \\
\text { objetivos e indicadores } \\
\text { de éxito preferentemente } \\
\text { expresados en términos } \\
\text { cuantitativos }\end{array}$ & $\begin{array}{l}\text { La rendición de cuentas } \\
\text { (accountability), } \\
\text { requiere claridad en la } \\
\text { declaración de metas }\end{array}$ \\
\hline 3 & $\begin{array}{l}\text { Gran énfasis en } \\
\text { el control de los } \\
\text { resultados }\end{array}$ & $\begin{array}{l}\text { La asignación de recursos } \\
\text { e incentivos, unidos a la } \\
\text { medición del desempeño } \\
\text { disuelven el extenso } \\
\text { centralismo burocrático }\end{array}$ & $\begin{array}{l}\text { Poner la atención más } \\
\text { en los resultados que en } \\
\text { los procedimientos }\end{array}$ \\
\hline 4 & $\begin{array}{l}\text { Cambio en la } \\
\text { desagregación de } \\
\text { las unidades en el } \\
\text { sector público }\end{array}$ & $\begin{array}{l}\text { Cambio en las anteriores } \\
\text { unidades monolíticas no } \\
\text { atándolas a los formularios } \\
\text { y descentralizándolas en } \\
\text { base a un presupuesto } \\
\text { propio con un control } \\
\text { básico }\end{array}$ & $\begin{array}{l}\text { Necesidad de crear } \\
\text { unidades administra- } \\
\text { bles separadas de la } \\
\text { provisión de intereses, } \\
\text { obteniendo ganancias y } \\
\text { ventajas en la eficiencia }\end{array}$ \\
\hline 5 & $\begin{array}{l}\text { Hacer competitivo } \\
\text { el sector público }\end{array}$ & $\begin{array}{l}\text { Cambiar los términos } \\
\text { contractuales del personal } \\
\text { y procedimientos públicos }\end{array}$ & $\begin{array}{l}\text { La competencia como } \\
\text { clave para disminuir los } \\
\text { costos y mejorar los } \\
\text { estándares }\end{array}$ \\
\hline 6 & $\begin{array}{l}\text { Poner atención en } \\
\text { el sector privado y } \\
\text { en sus estilos de } \\
\text { administración }\end{array}$ & $\begin{array}{l}\text { Erradicar el estilo militar } \\
\text { de administración por uno } \\
\text { de mayor flexibilidad en la } \\
\text { contratación e incentivos }\end{array}$ & $\begin{array}{l}\text { El auxilio de herramien- } \\
\text { tas del sector privado al } \\
\text { sector público }\end{array}$ \\
\hline 7 & $\begin{array}{l}\text { Poner atención } \\
\text { en el uso de los } \\
\text { recursos }\end{array}$ & $\begin{array}{c}\text { Disminución de los costos } \\
\text { directos, aumento de la } \\
\text { disciplina laboral, resis- } \\
\text { tencia a los sindicatos, } \\
\text { limitando los costos } \\
\text { complacientes de los } \\
\text { negocios. }\end{array}$ & $\begin{array}{l}\text { Necesidad de frenar la } \\
\text { demanda por el uso de } \\
\text { recursos públicos: "ha- } \\
\text { cer más con menos". }\end{array}$ \\
\hline
\end{tabular}

Fuente: Hood, 1991 
Aucoin (1990); Halligan (1997); Aberbach y Rockmen (1999) y Pierre (1995), vislumbran en esta nueva propuesta administrativa por un lado, la oposición a la burocracia sustituyéndola por la meritocracia basada en el desempeńo y en la evaluación de resultados, y por otro, la reducción del aparato estatal que fractura y niega la visión de la organización pública ${ }^{2}$. Contrastando con esta tendencia, Hal G. Rainey (2003) deja ver que las organizaciones públicas producen bienes y servicios que no son intercambiados en el mercado, ya que el gobierno se ve constreñido por múltiples conflictos, fines intangibles a nivel constitucional, de competencias técnicas y de valores de responsabilización (responsiveness). Por otro lado, H. George Frederickson (2005: 167), define algunas premisas que explican la ética pública en la Nueva Gestión Pública:

"1.- Con ausencia de leyes, reglas, convenciones sociales o reciprocidad social, los clientes o personas racionales y las empresas privadas actuarán sobre la base del autointerés. Aquí se asume lo racional como utilitarismo, por lo que se argumenta que las leyes democráticas, reglas y convenciones sociales inciden o influyen tanto en los individuos como en las empresas privadas para ajustar o adaptar el comportamiento auto-interesado en la dirección de los intereses colectivos.

2.- Bajo las condiciones democráticas, las instituciones gubernamentales tienen un sentido más público que las organizaciones no gubernamentales y las empresas privadas, por lo que los valores de justicia, igualdad y equidad están más impregnados en aquellas que en estas".

En este sentido, David Arellano y Enrique Cabrero (2005) en un sugerente trabajo denominado "La Nueva Gestión Pública y su teoría de la organización: ¿son argumentos antiliberales? Justicia y equidad en el debate organizacional público", han planteado el debate sobre las consecuencias de la Nueva Gestión
Pública y sus argumentos libertarios al estilo Nozick, R (1974) ${ }^{3}$ :

Consecuencia 1: La NGP produce una pérdida de la misión organizacional: las organizaciones públicas existen no sólo para producir servicios para los clientes, sino también para evitar la imposición de un valor social mejor. Las organizaciones públicas son creadoras de significado social. Las organizaciones públicas existen en una compleja red interorganizacional.

Consecuencia 2: El argumento libertario de la NGP elimina la concepción liberal de una sociedad plural y define al gobierno como una organización que persigue un solo fin: una estructura técnica eficiente para proveer servicios. Por lo tanto, produce un ethos precario de justicia: la justicia proviene de una organización técnica, no mediante organizaciones ni diálogo político.

Consecuencia 3: El costo de una visión individualista del mundo en el gobierno y en las organizaciones públicas.

Consecuencia 4: Las organizaciones meritocráticas esconden una pregunta importante ¿Quién define cuál mérito es socialmente importante?

Consecuencia 5: Indiferencia hacia la justicia pública y la importancia del imperio de la ley. ¿Qué hacer cuando actuar justamente u obedecer la ley crea resultados "ineficientes"?

Podemos afirmar que si la NGP no responde a un concepto de justicia basado en la razón pública, entonces su ética es una ética privada material y de contenido carente de obligación pública emanada por consenso. Una ética que no establece criterios para que los espacios sociales, ámbitos de poder y del derecho estén abiertos a la generación de valor público.

\footnotetext{
La Nueva Gestión Pública tiene tendencia a ver los resultados en el marco de una cultura de accountability auditable jerárquica y coercitiva, ya que la información está centralizada en pocas manos para gestionar el performance del público. Además, una serie de problemas se asocian a este paradigma: la brecha de la implementación a la manipulación de los indicadores de resultados, así como la frustración acerca de no tomar en cuenta los efectos de los factores externos, haciendo más hincapié en los resultados internos (Shore, C., and Wright, S; 2000).
}

\footnotetext{
Este autor, representante de las ideas libertarias, parte de que los seres humanos deben ser dueños de sí mismos (self-ownership) como el único medio para crear una sociedad justa. Una sociedad es justa o imparcial si cada individuo es capaz de perseguir sus propios objetivos sin la interferencia de otras fuentes externas, como el Estado.
} 


\section{Valor público y ética pública: dos puntos clave en la gestión pública contemporánea}

A diferencia de las dos tendencias éticas anteriores, esta basa su concepto de poder en la conjunción de la libertad individual y civil con la autoridad legítima del Estado, regulando de este modo sus relaciones conforme a un orden institucional consensuado promotor del interés público y garante de los derechos humanos. De este modo, el reconocimiento público y crítico de los ciudadanos podría ser la forma de legitimar el poder, por lo que la astucia y la capacidad política combinada con la coerción legal podrían lograr la legitimidad social, sustento esta de la autoridad estatal. Para la acción política del Estado, esta tendencia reconoce el marco normativo de justicia que, por supuesto, no es de naturaleza ontológica ya que se inspira en un orden constitucional que exige participación democrática. Ello implica, entonces, la potenciación del equilibrio de poderes y del Estado de derecho, generando un régimen político democrático donde la rendición de cuentas y la participación son elementos clave.

A partir de este último comportamiento, pudiéramos empezar a hablar de una ética de la política democrática que, al decir de Gianfranco Pasquino (2000), para que se formule es indispensable que la política se presente como un ámbito autónomo, capaz de proporcionarse sus propias reglas de constitución, de funcionamiento y de transformación. $\mathrm{O}$ como afirma Niklas Luhmann, "una ética política tendría sobre todo, que tomar en cuenta la autodirección del sistema" por lo que "el sistema político no está para ser controlado de acuerdo con bases del criterio moral; puede controlarse así mismo sólo políticamente" (1998: 106-107). En este sentido, vale afirmar que la ética debe verse, además de una actitud individual pura, como instituciones políticas y económicas justas. Es esta la razón por la cual la ética pública es una variable en gran medida dependiente del sistema político existente en cada sociedad, no sólo del grado de inmoralidad de los líderes políticos. Así, podemos afirmar que mientras más justas sean las instituciones mayor anclaje tendrá la ética en el sector público, ya que el principio de publicidad ligado al de transparencia así como el de legalidad, dan las bases de las reglas del juego para que funcionarios, políticos y ciudadanos encuentren puntos de vinculación. Niklas Luhmann lo ha expresado acertadamente cuando afirma que:
“... hay que volver manifiestas las acciones que posiblemente no se realizarán o que no tendrán los efectos que les han sido adscritos. Lo que importa es que uno sea visto continuamente, y se debe prestar atención a las observaciones y a las condiciones con que lo observan a uno. Las intenciones no tienen que ser mantenidas en secreto, sino que deben ser anunciadas. El sistema político... se especializa en la conversación, es decir en la presentación de los esfuerzos mediante decisiones racionales. Y el riesgo consiste entonces en que la mera acústica verbal lleva a alimentar expectativas que luego no pueden ser satisfechas o que no se quieren satisfacer. Este cambio del secreto de Estado a la publicidad como medio de comunicación cambia la situación de riesgo, y en ambos sentidos: en lo que respecta a la atención que se presta a los riesgos de la sociedad, y a los que se dan debido al riesgo propio de la política" (2006: 201).

Precisamos entonces, que si las instituciones políticas son justas es porque portan en sí valores y deberes que quienes se impliquen en ellas deben respetar ${ }^{4}$. Manuel Villoria Mendieta afirma que "no se trata tanto de rogar a la clase política que incorpore a su conducta principios y reglas éticas derivadas de la propia esencia de la democracia, que también, sino esencialmente de construir sistemas políticos que incentiven la moralidad pública y promover sistemas sociales que sancionen eficazmente la inmoralidad en la actuación política" (2006: 140). De esta manera, frente a la inmoralidad política es necesario pedir una política democrática de mayor calidad que responda tal como dice el mismo Villoria Mendieta "a un temor ante la pérdida de capacidad del sistema político para procesar demandas y dar respuestas coherentes" (2006:146). Es la razón por la cual recientemente la discusión sobre la calidad de la democracia plantea la necesidad de tomar en serio las instituciones para hacer valer la legalidad, las garantías ciudadanas y la justicia (Diamond, Larry and Leonardo Morlino; 2005).

La literatura institucionalista -según Gerardo L. Munck (2004) - ofrece también ideas que deberían incorporarse al debate sobre la calidad de las instituciones democráticas. En este sentido, estas pueden

\footnotetext{
Los derechos humanos -al menos los derechos civiles y políticos- son el patrón moral básico de carácter universal y generalizable, patrón que es compatible con la búsqueda individual, privada y razonable del bien.
} 
expresarse mediante dos relaciones distintas. Una, la relación entre ciudadanos y gobernantes; y dos, la relación del gobernante y los funcionarios públicos. La primera ha sido la preocupación de las investigaciones en esta tradición sobre todo en lo relativo a la rendición de cuentas y a la representación. Como podemos ver, la rendición de cuentas es un concepto fundamental a tomar en consideración cuando asumimos la política democrática de calidad ya que nos plantea el alcance y los diversos sistemas de control del poder. Viéndolo de esta manera, la noción de rendición de cuentas, según Andreas Schedler, "incluye, por un lado, la obligación de políticos y funcionarios de informar sobre sus decisiones y de justificarlas en público (answerability). Por otro lado, incluye la capacidad de sancionar a políticos y funcionarios en caso de que hayan violado sus deberes públicos (enforcement)" (2004:12). Esta noción nos lleva a definir lo que Guillermo O’Donnell (2002) ha denominado Accountability horizontal y Accountability vertical. Con la horizontal se refiere este autor, a las relaciones de control entre agencias del Estado que tienen autoridad legal y están fácticamente dispuestas y capacitadas para emprender acciones que van desde el control rutinario hasta sanciones legales, en relación con actos u omisiones de otros agentes o agencias del Estado que pueden ser calificadas como ilícitas. En otras palabras, nos referimos a un sistema intraestatal de controles. "En la teoría democrática, la expresión paradigmática de una relación horizontal de este tipo es la clásica división de poderes. En teoría los poderes Ejecutivo, Legislativo y Judicial se limitan y controlan mutuamente en un sistema balanceado de pesos y contrapesos" (Andreas Schedler; 2004). En otro sentido, la rendición de cuentas vertical se refiere a las relaciones de control de la sociedad hacia el Estado que implica la existencia de controles externos sobre el Poder Público y que describe una relación entre desiguales, entre superiores y subordinados. Este tipo de rendición de cuentas logra expresarse en las democracias representativas por dos vías: la rendición de cuentas electoral y la rendición de cuentas societal o social'5. Estos dos tipos de accountability o rendición

\footnotetext{
La accountability social es un mecanismo de control vertical, no electoral, de las autoridades políticas basado en las acciones de un amplio espectro de asociaciones y movimientos ciudadanos, así como también en acciones mediáticas. Las iniciativas de estos autores tienen por objeto monitorear el comportamiento de los funcionarios públicos, exponer y denunciar actos ilegales de estos y activar la operación de agencias horizontales de control (Enrique Peruzzotti y Catalina Smulovitz; 2002:32).
}

de cuentas vertical tienen un sentido complementario. Mientras que el instrumento fundamental de la accountability electoral -representación- que son los partidos políticos, ya no cumple cabalmente la función de control en el sistema político ${ }^{6}$, la accountability social o societal incorpora la esfera pública y la sociedad civil para completar y complementar, más que reemplazar, la accountability de la representación (Andrew Arato; 2002).

En cuanto a la institución de la representación, Adam Przeworski (1998) ha venido señalando que la conexión entre la democracia y la representación se basa en que en democracia los gobiernos son representativos porque son electos. "Si las elecciones son libremente disputadas, si la participación es ilimitada, y si los ciudadanos gozan de libertades políticas, entonces los gobiernos actuarán de acuerdo con el mejor interés del pueblo" (1998:9). De allí -señala el mismo autor-, que la estructura básica de la institución de la representación se pudiera resumir en los siguientes elementos: a.- los mandatarios, aquellos que gobiernan, son electos a través de las elecciones; b.mientras que los ciudadanos son libres para discutir, criticar y demandar en cualquier circunstancia, no están capacitados para ordenar qué hacer al gobierno; c.- el gobierno se encuentra dividido en órganos separados que pueden controlarse recíprocamente, y está limitado en cuanto a lo que puede hacer, por una Constitución; d.- los gobernantes están sometidos a elecciones periódicas.

La segunda relación vinculada al institucionalismo, la del gobernante y los funcionarios públicos, cobra también relevante importancia porque presenta los retos de los funcionarios electos de buscar controlar a la burocracia del Estado en la implementación

\footnotetext{
Pese a su importancia en las democracias modernas, este mecanismo encuentra su debilidad de control cuando los gobernantes manipulan en su beneficio la información, generando que esta sea asimétrica. De esta manera, mediante la estrategia de ocultar las políticas impopulares, la persuasión de los votantes y la aceptación de políticas impopulares de parte de los gobernantes, se influye en la opinión pública, reforzando el apoyo político a la hora de rendir cuentas, ya que el poder de los votantes es muy limitado para juzgar el resultado de las mayorías de las políticas del gobierno (José María Maravall, 2003; Adam Przeworski, 1995). Dado a la falla de este mecanismo, Guillermo O'Donnell (2002), sugiere que las acciones de accountability social -particularmente si son vigorosas, sostenidas y obtienen una extensa atención pública- pueden enviar fuertes señales a los políticos que desean ser electos o reelectos.
} 
de las políticas públicas? ${ }^{7}$ De allí que el grado de satisfacción de los actores frente a las instituciones políticas y administrativas del Estado constituyen una medida cierta de calidad de la democracia. En el caso latinoamericano, la debilidad de la burocracia ha contribuido a la debilidad del Poder Ejecutivo de los países ya que ha servido más como un recurso privado de los partidos políticos que como actor profesional que responda a una ética pública. Con la práctica del uso de las instituciones para reforzar el poder partidista, las burocracias, haciendo caso a los intereses políticos, dificultan el desarrollo justo de las instituciones, así como la labor de otros actores partidos de oposición, organizaciones de la sociedad civil- en el fortalecimiento del mismo. Idealmente -dice Adam Pzreworski (2004: 196)-, "lo que uno desearía sería una burocracia que implementara aquellas decisiones tomadas por los políticos pero que están orientadas al interés general, sin llegar a transformarse en un instrumento de aquellos intereses que sean meramente partidarios". Para ello, debe cumplirse con el principio de la legalidad, así como el apego a las reglas del juego, es decir, aquellas reglas de comportamiento predispuestas por un sistema político para los funcionarios públicos en relación con los ciudadanos ${ }^{8}$.

De esta manera, para que en una democracia esta relación se convierta en una pieza fundamental de sus instituciones, aquella debe tomar una dimensión eminentemente deliberativa que facilite la accountability social o societal y la inclusión de la sociedad en las acciones públicas (políticas y decisiones públicas). Por una parte, la accountability social o societal se vería "como un mecanismo de control vertical, no electoral, de las autoridades

Según Kenneth A. Shepsle y Mark S. Bonchek, “... la actividad de los políticos es la formulación de políticas públicas y los procedimientos constitucionales especifican cómo deben hacerlo; pero, aun las políticas formuladas de acuerdo con las estipulaciones constitucionales más rigurosas, no son la última palabra. Las políticas no se implementan solas. Alguien debe ejercer la autoridad y gastar los recursos otorgados por una ley, y ese "alguien" es el burócrata; sin embargo, si la política que realmente pone en práctica un agente burocrático se aleja de la que formularon sus mandantes políticos, significa un desliz o desviación de la agencia" (2005:354).

8 La noción de "juego limpio" de John Rawls (1986) expresa no sólo la obligación de seguir las normas que uno ha aceptado por consenso, sino de que cuando se aceptan los beneficios de su práctica común se tiene la obligación de actuar de acuerdo con ella, cuando le llega la hora de hacerlo, pues habitualmente se considera inicuo (unfair) que uno acepte los beneficios de una práctica pero que uno renuncie a hacer lo que le corresponde para mantenerla. políticas basado en las acciones de un amplio espectro de asociaciones y movimientos ciudadanos, así como también en acciones mediáticas. Las iniciativas de estos actores tienen por objeto monitorear el comportamiento de los funcionarios públicos, exponer y denunciar actos ilegales de estos y activar la operación de agencias horizontales de control" (Enrique Peruzzotti y Catalina Smulovitz; 2002:32). Con el control de temas, políticas o funcionarios públicos estos mecanismos sociales pueden supervisar no sólo la legalidad de los procedimientos seguidos por los actores gubernamentales y políticos, sino la producción de servicios de alta calidad, la consulta al público sobre estos servicios y la forma en que se prestarán, así como la implicación del ciudadano en su prestación. Es de esta manera como se le daría sentido a las tres dimensiones de la accountability: la dimensión de información ya que por medio de la presión social se obligaría al poder a abrirse a la inspección pública; la dimensión argumentativa, en el entendido que por medio de una efectiva y legítima participación ciudadana se forzaría a explicar y justificar las acciones y decisiones gubernamentales $y$, la dimensión punitiva, con lo que se tendría asegurado que el poder gubernamental podría ser supeditado a la amenaza de las sanciones, pero en este caso no formales sino simbólicas.

Por otra parte, la inclusión de la sociedad en las acciones públicas (politicas públicas y decisiones públicas) no sería posible sin un impulso de una democracia más allá de la representación. Precisando entonces, podríamos afirmar que la comprensión de la política pública en un contexto de democracia más allá de la representación, nos lleva a detectar los espacios públicos de deliberación. El espacio público lo veríamos entonces como la gama heterogénea y diversa de posibilidades, de visiones, de creencias, de percepciones, de problemáticas y de soluciones donde el diálogo y la deliberación permiten sistematizar en forma legítima acuerdos y consensos para la toma de decisiones públicas. Esta visión nos llevaría a dos cuestiones importantes al hablar de políticas públicas: por un lado, -como dice Jan Kooiman (2004) - a la creación de oportunidades sociales, además de solución de problemas públicos y, por el otro, al incremento del valor público. El valor público se refiere al valor creado por el Estado a través de servicios, leyes, regulaciones y otras acciones. En una democracia, estos valores son definidos en última instancia por el público usuario. Los valores determinados por las preferencias ciudadanas 
expresadas a través de una variedad de medios y reflejados a través de las decisiones de los políticos electos (Kelly y Muers; 2002).

De esta manera este concepto asume que la gente tiene la capacidad y la libertad para expresar sus preferencias respecto a las actividades y resultados de la Administración Pública. También asume que las Administraciones Públicas tienen la voluntad y la capacidad para acomodar sus objetivos a las preferencias ciudadanas; y más que eso, asume que al entregar el valor público requerido, la gente estará dispuesta a pagar por él con dinero, con el voto, u ofreciendo su tiempo para colaborar con el gobierno. Se trata de una relación transparente entre ciudadano y gobierno cuyo aspecto central es la capacidad de las administraciones para orientar su trabajo hacia lo que más le importa a la gente, y a darles servicios (Guido Bertucci; 2005). Visto así, se necesita que el tipo de liderazgo del gobierno cambie de proveedor autoritario de soluciones que usa su autoridad sólo para la toma de decisiones de la política pública a un gobierno que genere ambientes y contextos en que los ciudadanos hagan frente a los problemas colectivos para decidir juntos sobre lo que ellos quieran hacer (Moore; 1995). En este sentido, expresa el mismo Moore (1995) que la negociación, la deliberación pública y el acuerdo político se convierten en instrumentos necesarios para establecer acuerdos sobre lo que es más valioso para la sociedad en su conjunto. Y es sobre la base del aprendizaje social -idea asociada a la deliberacióny el liderazgo en que las acciones de los ciudadanos pueden inventar soluciones y movilizar acción. "Este aspecto debe ser particularmente importante cuando la "solución" al problema público requiere muchos individuos para inventar sus propias adaptaciones a los problemas reales a los que ellos le hacen frente (Moore; 1995:183).

Así, la gestión política es una herramienta clave que los funcionarios públicos deben manejar para hacer efectivo su trabajo. Pero a su vez esta se pudiera ver muy sensible éticamente; sin embargo, se hace necesario ya que los funcionarios públicos tienen la responsabilidad compartida con otros actores gubernamentales y con los ciudadanos, para decidir qué sería lo más recomendable producir con los recursos públicos. Esto nos lleva a pensar en una gestión donde el desafío ético del liderazgo público es un punto esencial, por lo que el concepto de valor público y de rendición de cuentas (accountability) debe estar presente en los servidores públicos. También la ética de la deliberación pública se manifiesta cuando el funcionario público establece el marco para que ciudadanos y actores privados y gubernamentales puedan institucionalizar los procedimientos $\mathrm{y}$ presupuestos comunicativos, así como la interacción de deliberaciones institucionalizadas con opiniones públicas desarrolladas informalmente?

Es así mismo como se generaría el valor público a través de respuestas a problemas relevantes para los beneficiarios y ciudadanos; la apertura de nuevas oportunidades para generaciones actuales y/o futuras; procesos que construyen ciudadanía, democracia y capital social; y procesos que demuestran el buen uso de recursos públicos expresado en el buen gobierno.

En esta línea, para un gobierno con una ética pública democrática y que genere valor público, son indispensables los diez comportamientos siguientes:

1. El gobernante deberá guiar los destinos de una comunidad de individuos, preferentemente dentro del orden democrático y la prosperidad.

2. Por definición, ningún actor político y funcionario público tiene jamás en sus manos todo el poder por un periodo de tiempo indefinido, ni tiene nunca la oportunidad de ejercerlo sin control ni contrapesos.

3. Sólo donde exista la posibilidad de elegir se puede escoger entre una mayor o menor ética de los comportamientos políticos. La presencia de alternativas de comportamientos éticamente válidas se demuestra justamente con el reconocimiento de la derogación y con la existencia de posibilidades de elección.

4. Que las personas cuenten siempre con la posibilidad constante de aspirar a gobernar en una libre competencia, posiblemente paritaria, transparente y periódica. Un comportamiento no ético es aquel que apunta a la marginación y destrucción de los demás actores, y todos los que reducen el pluralismo.

5. La ética en una sociedad democrática sostiene que es profundamente incorrecto que el dinero influya en la competencia política y en las

\footnotetext{
Sanderson (2000) afirma que el aprendizaje de las organizaciones públicas requiere competencia comunicativa o una discusión abierta y de libre argumentación tanto de los funcionarios públicos como del público de las "distorsiones" debido al ejercicio coercitivo del poder y la ideología.
} 
decisiones políticas y públicas. La democracia nace justamente para que los votos y el número cuenten más que el dinero y los recursos.

6. La ciudadanía debe contar con una fuerte creencia en la democracia como un valor en sí mismo.

7. La formación ciudadana implica los valores siguientes: libertad, tolerancia, solidaridad, justicia, prudencia, respeto al orden jurídico, diálogo y deliberación pública.

8. La ciudadanía debe disponer de medios abiertos y eficaces de participación en las políticas públicas de mayor relevancia para la sociedad.

9. La rendición de cuentas de las autoridades a la ciudadanía es una condición democrática.

10. Las relaciones entre las organizaciones de la sociedad civil, el sector privado y el gobierno deben estar abiertas al escrutinio público.

\section{A manera de reflexión}

A lo largo de esta ponencia fuimos delineando los comportamientos éticos más importantes vinculados con las diferentes visiones de gestión pública. En este caso, la administración pública tradicional, la Nueva Gestión Pública y la gestión pública sustentada en el Valor Público. Se pudo constatar que la ética pública es entendida de manera diferente en las tres visiones de gestión. Mientras que para la administración pública tradicional la ética pública tiene su asidero en la legitimidad de la acción gubernamental emanada sólo de la legalidad y de la intencionalidad de dicha acción y para la NGP son los resultados, producto de decisiones tecnocráticas aisladas de la razón pública, para la visión del Valor Público, la ética pública no está basada sólo en la legalidad, sino en la responsabilidad sobre las consecuencias prácticas que resultan de la acción, legitimada por los hechos y por la capacidad de resolver problemas. Ello nos introduce a diversas posibilidades de acción práctica en la administración pública. Por un lado, las implicaciones del diálogo como conversación estructurada a partir de espacios de conflictos y de participación de actores que disponen de un mínimo de información e interés para hacerlo; por otro lado y como consecuencia, el mejoramiento de la eficiencia y la eficacia dadas las reducciones de las resistencia del entorno como producto de una administración pública interactiva, y, por último, como eje clave y articulador, el mejoramiento del rendimiento institucional enten- dido como la capacidad de las instituciones públicas de dar respuestas a las necesidades sociales y de ser efectiva en sus actuaciones o interacciones con la sociedad, es decir, los acuerdos y la consecución de objetivos vía intervenciones directas o indirectas para generar las tomas de decisiones. Ello nos lleva a afirmar que la participación de actores diferentes del gobierno y funcionarios públicos en la administración pública, expresadas en la deliberación de la agenda pública y en el nuevo control social de las decisiones públicas, pueden contribuir a un rendimiento institucional en el marco de una legitimidad de la ética pública.

Asistimos entonces a un escenario en el que la legitimidad de la acción gubernamental, del ámbito público y de la ética pública no se deriva sólo de la legalidad ni tampoco sólo de la intencionalidad de dicha acción, sino fundamentalmente de la responsabilidad sobre las consecuencias prácticas que resultan de la acción. La acción pública entonces, enmarcada en una ética basada en la interacción democrática entre actores públicos y no públicos, toma importancia en la administración pública, y en consecuencia, en el análisis e implementación de la política pública, y por supuesto en la tarea del Estado ${ }^{10}$. Esta afirmación es central en el debate sobre la legitimidad democrática y la gestión pública ${ }^{11}$.

De esta manera pues, cuando se plantea el desafío de una reforma política de la Administración Pública en el marco de la ética pública, podríamos asumir, por

10 El vacio ético en los gobiernos o en sus funcionarios se refleja en sus decisiones, en las políticas públicas. Ocurre cuando ellos eligen pensando en los beneficios de los grupos de interés, no en la población. La falta de ética no es una cuestión declarativa, sino que se manifiesta por una desviación de recursos públicos que es injusta y aumenta la desigualdad en la sociedad civil (Rodolfo Arland, 2002).

11 En las décadas del 90 y del 2000 se llevaron procesos como reformas administrativas y de Estado, fortalecimiento democrático, y reformas estructurales de la economía en el marco del impacto de la globalización. Pero a su vez estos procesos fueron poco a poco alterados por revueltas sociales que sobrepasaron las instituciones recientemente construidas. Vale destacar -y es el punto de partida nuestro- que estos aspectos de los procesos de cambio no tocaron los contenidos sustantivos de la democracia -legitimidad de la ética pública- que dieran un sentido más allá de los contenidos procedimentales, fundamentalmente electorales. Ello derivó en crisis de los partidos políticos, mantenimiento de estructuras clientelares, así como el patrimonialismo de la burocracia del Estado que dio como resultado no sólo la baja credibilidad y el desprestigio de las instituciones democráticas claves, tales como los partidos políticos, el poder legislativo, el Estado de derecho, sino también de la legitimidad cada vez más lejana de los consensos para la gobernabilidad democrática (Freddy Mariñez Navarro; 2, 2011). 
un lado, como un espacio nuevo de regeneración democrática que se plantee, promueva, apoye y sustente los derechos humanos y, por el otro, por el hecho de que los ciudadanos identifiquen conscientemente aquello que desean o necesitan. En este sentido, las actitudes tanto del funcionario público como de los ciudadanos podrían tener una importancia fundamental para que las prácticas en la gestión pública estén sujetas al marco de la legalidad, y también para que los servicios públicos suministrados por el Estado a los ciudadanos se lleven a cabo con efectividad, eficacia, transparencia y rendición de cuentas.
El análisis ético de estas tres visiones de gestión-administración pública nos lleva a ver cuatro deseos clave. Uno, que se redistribuyan adecuadamente las rentas y las cargas y beneficios colectivos; dos, que este proceso de redistribución se realice con calidad, es decir con eficacia, efectividad y eficiencia; el tercero está relacionado con que las actuaciones públicas se ajusten a la ley, y el cuarto con la responsabilidad de los resultados e impactos. La concreción de estos deseos va a depender del proyecto ético de gestión pública a implementarse. 
Aberbach, Joel y Rockmann, Bert. 1999.

"Reinventar el Gobierno: problemas y perspectivas". Gestión y Análisis de Politicas Públicas. 15, INAP, mayo/ agosto.

Aguilar Villanueva, Luis F. 2007. El aporte de la política pública y la nueva gestión pública a la gobernanza. XII Congreso Internacional del CLAD sobre reforma del Estado y Administración Pública. República Dominicana, 30 octubre - 2 de noviembre.

Arland, Rodolfo. 2002. Ética o corrupción. Dilema del nuevo milenio. Fundación Estado y Sociedad. Documento de trabajo No. 3. Argentina: Serie Transparencia. Mendoza.

Arato, Andrew. 2002. "Accountability y sociedad civil”. En Enrique Peruzzotti y Catalia Smulovitz Controlando la politica. Ciudadanos y Medios en las nuevas democracias Latinoamericanas. Argentina: Tema Grupo Editorial SRL.

Arellano, David y Enrique Cabrero. 2005. "La nueva gestión pública y su teoría de la organización: ¿son argumentos antiliberales? Justicia y equidad en el debate organizacional público". Gestión y Política Pública XIV(3): 599-618.

Aucon, P. 1990. "Administrative Reform in public management: Paradigms, principles, paradox and pendulums". Governance International Journal of Policy and Administration 3(2).

Barzelay, Michael y Babak J. Armajani. 2000. Atravesando la burocracia. Una nueva perspectiva de la Administración Pública. México: Fondo de Cultura Económica

Bertucci, Guido. 2005. "Gobierno digital y valor público”. En Política Digital. Innovación.

Bobbio, Norberto. 2008. El futuro de la democracia. Quinta reimpresión. México: Fondo de Cultura Económica.

Burdeau, Georges. 1992. L'Etat, éditions du Seuil, París.

Cunnil Grau et ál. Politica y gestión pública. CLAD. Argentina: Fondo de Cultura Económica.

Deutsch, Karl. W. 1993. Politica y gobierno. México: Fondo de Cultura Económica.
Diamond, Larry and Leonardo Morlino. 2005. Assessing the quality of democracy. The Johns Hopkins University Press.

Halligan, J. 1997. New public sector models: reforme in Australia and New Zealand. In Lane, J. (ed.) Public sector reforme: rationale, trends and problems. London, Sage.

Henry, Nicholas L. 2001. "La raíz y las ramas: peripecias de la Administración pública hacia el futuro". En Naomi B. Lynn y Aaronm Wildavsky. (Comp.) Administración Pública. El estado actual de la disciplina. México: Fondo de Cultura Económica.

Herring, E. Pendleton. 1999. La administración pública y el interés público. En Shafritz, Jay M. y Albert C. Hyde. Clásicos de la Administración Pública. México: Fondo de Cultura Económica.

Hood, Christopher. 1991. "A Public Management for All Seasons". Public Administration 69(1).

Easton, David. 1997. Enfoque sobre teoría politica. Argentina: Amorrortu Editores.

1965. A Framework for Political Analysis. Englewood Cliffs, N.J.: Prentice-Hall.

Frederickson, H. George. 2005. "Public Ethics and New Managerialism: An Axiomatic Theory". In H. George Frederickson and Richard K. Ghere. Editors) Ethics in Public Management. M.E. Sharpe, New York.

Kelly, G., Mulgan, G., Muers, S. 2002. "Creating Public Value: An Analytical Framework for Public Service Reform", Discussion paper prepared by the Cabinet Office Strategy Unit, United Kingdom.

Kooiman, Jan. 2004. "Gobernar en gobernanza" Revista Instituciones y desarrollo No. 16 (171-194), Barcelona, 2004. www.iigov.org (Consultado, 29-3-2008).

Luhmann; Niklas. 1998. Teoría de los Sistemas Sociales. México: Universidad Ibeoramericana.

$$
\text { 2006. Sociología del riesgo. }
$$
México: Universidad Iberoamericana. Maesschalk, J. 2004. Approaches to Ethics Management in the Public
Sector. A Proposed Extension of the Compliance-Integrity Continuum. Public Integrity 7(1): 21-42.

Maravall, José María. 2003. El control de los politicos. Madrid: Taurus.

Marińez Navarro, Freddy. 2011. Legitimidad democrática para la inclusión ciudadana. 12 Ed. Foro de Biarriz, Santo Domingo, República Dominicana.

Mayntz, Renate. 2001. "El Estado y la sociedad civil en la gobernanza moderna". Revista del Clad Reforma del Estado y Democracia. No. 21 (oct.). (1-8).

Moore, Mark H. 1995. Creating Public Value. Strategic Management in Government. Harvard University Press, Cambridge, Massachussets.

Munck, Gerardo L. 2004. "La política democrática en América Latina: contribución desde una perspectiva institucional". Política y gobierno $\mathrm{XI}(2)$.

Nozick, R. 1974. Anarchy, State, and Utopia. New York: Basic Books.

O’Donnell, Guillermo. 2002. Acerca de varias accountabilities y sus interrelaciones. En Enrique Peruzzotti y Catalia Smulovitz Controlando la política. Ciudadanos y Medios en las Nuevas Democracias Latinoamericanas. Argentina: Tema Grupo Editorial SRL.

OECD. 1998. Principles for managing ethics in the public service. Recommendation.

Osborne, David y Ted Gaebler. 1997. La reinvención del gobierno. La influencia del espiritu empresarial en el sector público. Espańa: Paidós Editores.

Pasquino, Gianfranco. 2000. La democracia exigente. España: Alianza Editorial.

Peces-Barba, Gregorio. 2004. Ética, poder y derecho. Reflexiones ante el fin de siglo. México: Editorial Fontamara.

Peters, Guy B. 2006. Democracia y administración pública. Una conexión emergente. Administración \& Ciudadanía 1: 29-46.

2003. La capacidad para gobernar: ¿retrocediendo hacia el centro? Revista del CLAD reforma y democracia 27: 1-13. 
2001. The future of governing. Second edition revised. University Press of Kansas.

Peruzzotti, Enrique y Catalina Smulovitz. 2002. Accountability social: la otra cara del control. En Enrique Peruzzotti y Catalia Smulovitz. Controlando la politica. Ciudadanos y medios en las nuevas democracias latinoamericanas. Argentina: Tema Grupo Editorial SRL.

Pierre, J. 1995. (Ed.) Bureaucracy in the Modern State: an introduction to comparative public administration. Aldershot, Edward Elgar.

Przeworski, Adam. 1995. Democracia y mercados. Cambridge University Press.

1998. Democracia y participación. Revista CLAD Reforma y Democracia. 10.

. 2004. Politica y Administración Pública. En Luis Carlos BresserPereira, Nuria.

PUMA. s. f. Policy Brief No. 4.
Rainey, Hal G. 2003. Understanding and Managing Public organizations. Third Edition. Jossey-Bass publishers, USA.

Rawls, John. 1986. La justicia como equidad. Materiales para una teoría de la justicia. Madrid: Tecnos.

Sanderson, I. 2000. "Evaluation in Complex Policy Systems". Evaluación 6(4): 433-454.

Shafritz, Jay M. and Albert C. Hyde. 1999. Clásicos de la Administración Pública. México: Fondo de Cultura Económica. Universidad Autónoma de Campeche.

Shepsle, Kenneth A., y Mark S. Bonchek. 2005. Las fórmulas de la politica. Instituciones, racionalidad y comportamiento. México: TaurusCIDE.

Schedler, Andreas. 2004. ¿Qué es la rendición de cuentas? México: Instituto Federal de Acceso a la Información (IFAI).

Shore, C. \& Wright, S. 2000. Coercitive accountability: The rise of audit cultura in higher education. In M. Strathern (ed.) Audit Cultures, London: Routledge.

Thöenig, Jean-Claude.. 1997. Política Pública y Acción Pública. Gestión y política pública VI(1).

_-_-___. 2005. "Pour une épistémologie des recherché sur l'action publique". Paru dans D. Filatre et G. de Teressac (coord.) Les dynamiques intermédiaires au coeur de l'action publique. Toulouse, 2005.

Villoria Mendieta, Manuel. 2006. La corrupción política. España: Editorial Síntesis.

Weber, Max. 1997. Economía y sociedad. México: Fondo de Cultura Económica. 1998. El político y el cientifico. México: Colofón, S.A.

Wilson, Woodrow. 2005. [1887]. El estudio de la administración. http:// www.inep.org. Political Science Quarterly II(2). 